\title{
Protocol: fine-tuning of a Chromatin Immunoprecipitation (ChIP) protocol in tomato
}

\author{
Martiniano M Ricardi, Rodrigo M González, Norberto D lusem
}

\begin{abstract}
Background: Searching thoroughly for plant cis-elements corresponding to transcription factors is worthwhile to reveal novel gene activation cascades. At the same time, a great deal of research is currently focused on epigenetic events in plants. A widely used method serving both purposes is chromatin immunoprecipitation, which was developed for Arabidopsis and other plants but is not yet operational for tomato (Solanum lycopersicum), a model plant species for a group of economically important crops.

Results: We developed a chromatin immunoprecipitation protocol suitable for tomato by adjusting the parameters to optimise in vivo crosslinking, purification of nuclei, chromatin extraction, DNA shearing and precipitate analysis using real-time PCR. Results were obtained with two different antibodies, five control loci and two normalisation criteria.

Conclusion: Here we provide a chromatin immunoprecipitation procedure for tomato leaves that could be combined with high-throughput sequencing to generate a detailed map of epigenetic modifications or genomewide nucleosome positioning data.
\end{abstract}

\section{Introduction}

Emerging high-throughput methods and bioinformatics technologies have great potential to accelerate the discovery of specific DNA regulatory elements that interact with transcription factors (TFs). However, the vast majority of plant cis-elements corresponding to the majority of TFs are unknown [1], in part due to a lack of optimised experimental methods to be carried out prior to genome-wide data analyses.

By contrast, a great deal of research is currently focused on epigenetic events in plants. This topic is particularly interesting because in plants, unlike animals, acquired epigenetic changes can be transmitted to progeny since germ cells differentiate from somatic tissues present in an adult individual. In addition, stable patterns of gene expression necessary for differentiation and long-term adaptation can be mitotically and meiotically inherited in the form of active or silent epigenetic gene variants via mechanisms associated with chromatin

\footnotetext{
* Correspondence: norbius@fbmc.fcen.uba.ar

Departamento de Fisiología, Biología Molecular y Celular. IFIByNE-CONICET. Facultad de Ciencias Exactas y Naturales, Universidad de Buenos Aires, Argentina
}

() 2010 Ricardi et al; licensee BioMed Central Ltd. This is an Open Access article distributed under the terms of the Creative Commons Attribution License (http://creativecommons.org/licenses/by/2.0), which permits unrestricted use, distribution, and reproduction in any medium, provided the original work is properly cited. structure [2]. In this respect the role of histone modifications is becoming increasingly appreciated.

Chromatin immunoprecipitation (ChIP) is a widely used procedure both to identify novel TF-target genes and to examine histone modifications. It is currently used in Arabidopsis [3] but is not yet developed for use with tomato (Solanum lycopersicum), which is considered a model plant species for a group of economically important crops such as potato, pepper and eggplant.

Tomato has a reduced genomic size $(950 \mathrm{Mb})$, a short generation time and routine transformation technologies. Moreover, it shares the same haploid chromosome number and a high level of conserved genomic organisation with other Solanaceous plants [4]. Despite Arabidopsis being a model plant suitable for many purposes, it has a smaller gene repertoire than tomato $(25,000$ vs. $35,000)[5]$ as they belong to different families (Brassicaceae and Solanaceae, respectively) that diverged early in flowering plant evolution, 150 million years ago [6]. Consequently, there are gene families that appear smaller in the Arabidopsis genome compared to tomato such as the MADS-box genes involved in development and fruit ripening [7], as well as gene families that are even 
absent such as the ASR gene family [8], which is associated with water stress.

Since current ChIP protocols and commercial kits that have been designed for or tested with other plant species [9] do not work for tomato tissues, our goal was to develop a reliable ChIP procedure for tomato. Therefore, we adjusted critical parameters of ChIP in order to optimise each successive step, particularly crosslinking and chromatin extraction.

\section{Materials and methods \\ Plant material}

Commercial tomato plants were grown under controlled environmental conditions with a photoperiod of 16 light hours and 8 dark hours and a mean temperature of $24^{\circ} \mathrm{C}$. Only healthy five-week plants were used in all experiments.

\section{Confocal microscopy}

An Olympus instrument model FV-300 was used. The software was Fluoview 3.3. The objective lens was $60 \times$ NA 1.4.

\section{Micrococcal nuclease digestion}

Nuclei were purified following the ChIP protocol from steps 6 to 14 and washed twice with nuclei resuspension buffer by $10 \mathrm{~min}$ of centrifugation at 12,000 × g. Micrococcal nuclease (Worthington Biochemical Corporation, Lakewood, NJ, USA) digestion was performed in $100 \mathrm{ul}$ for $20 \mathrm{~min}$ at $37^{\circ} \mathrm{C}$. The enzymatic reaction was stopped by resuming the ChIP protocol from step 35 (proteinase $\mathrm{K})$. The resulting DNA fragments were then extracted and precipitated according to steps 36-39.

\section{DNA physical shearing}

A Branson Sonic Dismembrator 102C instrument was used to achieve the necessary high-intensity ultrasound.

\section{Antibodies}

The antibodies used were of ChIP-grade quality and purchased from Abcam, Cambridge, UK (anti-H3: catalogue code \# 12079; anti-H3K9 me2: catalogue code \# 1220).

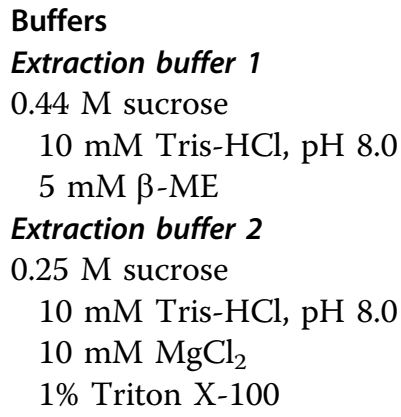

$5 \mathrm{mM} \beta$-ME

$1 \times$ protease inhibitor cocktail

\section{Percoll extraction buffer}

95\% V/V Percoll

$0.25 \mathrm{M}$ sucrose

10 mM Tris- $\mathrm{HCl}, \mathrm{pH} 8.0$

$10 \mathrm{mM} \mathrm{MgCl} 2$

$5 \mathrm{mM} \beta-\mathrm{ME}$

$1 \times$ protease inhibitor cocktail

Nuclei resuspension buffer

10\% Glycerol

50 mM Tris- $\mathrm{HCl}, \mathrm{pH} 8.0$

$5 \mathrm{mM} \mathrm{MgCl} 2$

$10 \mathrm{mM} \beta-\mathrm{ME}$

$1 \times$ protease inhibitor cocktail

Nuclei lysis buffer

$50 \mathrm{mM}$ Tris- $\mathrm{HCl}, \mathrm{pH} 8.0$

$10 \mathrm{mM}$ EDTA

$1 \%$ SDS

$1 \times$ protease inhibitor cocktail

\section{ChIP dilution buffer}

1.1\% Triton X-100

$1.2 \mathrm{mM}$ EDTA

$167 \mathrm{mM} \mathrm{NaCl}$

16.7 mM Tris- $\mathrm{HCl}, \mathrm{pH} 8.0$

$1 \times$ protease inhibitor cocktail

Low salt wash

20 mM Tris- $\mathrm{HCl}, \mathrm{pH} 8.0$

$150 \mathrm{mM} \mathrm{NaCl}$

$0.1 \%$ SDS

$1 \%$ Triton X-100

2 mM EDTA

High salt wash

$20 \mathrm{mM}$ Tris- $\mathrm{HCl}, \mathrm{pH} 8.0$

$500 \mathrm{mM} \mathrm{NaCl}$

$0.1 \%$ SDS

1\% Triton X-100

2 mM EDTA

LiCl wash

$0.25 \mathrm{M} \mathrm{LiCl}$

$1 \%$ NP-40

$1 \%$ sodium deoxicholate

1 mM EDTA

10 mM Tris- $\mathrm{HCl}, \mathrm{pH} 8.0$

TE buffer

10 mM Tris- $\mathrm{HCl}, \mathrm{pH} 8.0$

$1 \mathrm{mM}$ EDTA

Elution buffer

$1 \%$ SDS

$0.1 \mathrm{M} \mathrm{NaHCO}_{3}$ Micrococcal nuclease buffer $50 \mathrm{mM}$ Tris- $\mathrm{HCl}, \mathrm{pH} 8.5$

$5 \mathrm{mM} \mathrm{Mg}$ acetate

$25 \%$ glycerol 


\section{Protocol}

\section{Crosslinking}

1- Harvest 3-4 g of healthy young leaves and cut them into 5-10 mm pieces (we used 3-5 week- old plants).

2- Place no more than $1 \mathrm{~g}$ of cut leaves into a Falcon tube and rinse two times with $50 \mathrm{ml}$ of milliQ water by gently shaking.

3 - Remove all water and submerge the leaves in $37 \mathrm{ml}$ of $1 \%$ formaldehyde in cold extraction buffer 1 and vacuum infiltrate for $10 \mathrm{~min}$. The solution will boil, and the leaves should appear translucent.

4- Add $2.5 \mathrm{ml}$ of $2 \mathrm{M}$ glycine, mix well and vacuuminfiltrate for 5 additional min to stop crosslinking.

5- Remove buffer and rinse twice with cold milliQ water. Remove excess water as thoroughly as possible with a paper towel.

\section{Chromatin isolation}

6- Grind the tissue to a fine powder with a pre-cooled mortar and pestle and liquid nitrogen. At this step, the samples can be combined but we recommend to grind $1 \mathrm{~g}$ at a time in the same mortar.

7- Resuspend the powder in $30-40 \mathrm{ml}$ of cold extraction buffer 1 (see below for composition details). Unless otherwise specified, all of the following steps should be done at $0-4^{\circ} \mathrm{C}$.

8 - Filter sequentially through 80 and $11 \mu \mathrm{m}$ nylon mesh.

9- Spin the filtered solution for $20 \mathrm{~min}$ at $2,880 \times \mathrm{g}$.

10- Remove the supernatant and resuspend the pellet in $10 \mathrm{ml}$ of extraction buffer 2 (see below for composition details).

11- Incubate for $10 \mathrm{~min}$ on ice to lyse chloroplasts and spin for $20 \mathrm{~min}$ at $2,100 \times \mathrm{g}$.

12 - Remove the supernatant and resuspend the pellet in $4 \mathrm{ml}$ of extraction buffer 2 without Triton $\mathrm{X}-100$.

13- Spin for $20 \mathrm{~min}$ at $2,100 \times \mathrm{g}$ and resuspend the pellet in $4 \mathrm{ml}$ of Percoll extraction buffer.

14- Spin for $10 \mathrm{~min}$ at $12,000 \times \mathrm{g}$.

15- Carefully take the upper phase and dilute it at least 5 times into nuclei resuspension buffer (for composition, see below).

16- Spin for $10 \mathrm{~min}$ at $12,000 \times \mathrm{g}$.

17- Discard the supernatant and resuspend the pellet in $4 \mathrm{ml}$ of nuclei resuspension buffer. At this step, the samples can be stored at $-20^{\circ} \mathrm{C}$

\section{Nuclei lysis and DNA shearing}

18- Spin for $10 \mathrm{~min}$ at $12,000 \times \mathrm{g}$.

19- Resuspend the pellet in $0.5 \mathrm{ml}$ of nuclei lysis buffer.

20- Sonicate chromatin for $10 \mathrm{sec}, 5$ times at $15 \%$ power setting to shear DNA into 200- to 1000-bp fragments.

21 - Centrifuge $5 \mathrm{~min}$ at $21,000 \times \mathrm{g}$ to pellet debris.

\section{Chromatin immunoprecipitation}

22- Transfer the supernatant into a new tube and quantify the DNA using the Quan-It dsDNA Broad-Range Assay kit (Invitrogen, San Diego, CA, USA). Alternatively, a small amount of the chromatin extract (10-20 $\mu \mathrm{l})$ can be quantified by conventional GeneQuant analysis following de-crosslinking and phenol/chloroform purification. The minimal amount of DNA required to continue is about $18 \mu \mathrm{g}$, sufficient for processing the negative control $(5 \mu \mathrm{g})$, the positive control $(5 \mu \mathrm{g})$, the tube with the biologically relevant sample $(5 \mu \mathrm{g})$ and the INPUT $(2 \mu \mathrm{g})$.

23- Block $40 \mu \mathrm{l}$ of protein A/G Plus agarose beads (Santa Cruz Biotechnology, Santa Cruz, CA, USA) with sheared salmon sperm DNA (at $0.2 \mathrm{mg} / \mathrm{ml}$ final concentration) and $0.5 \mathrm{mg} / \mathrm{ml} \mathrm{BSA.}$

24- Split the chromatin sample (approx. $450 \mu \mathrm{l}$ ) into three tubes of equal volume $(150 \mu \mathrm{l})$ and dilute 1:10 (up to $1.5 \mathrm{ml}$ ) in ChIP dilution buffer (see below for composition details).

25- Wash the blocked beads three times with $1 \mathrm{ml}$ ChIP dilution buffer. Pellet beads by centrifuging for 5 $\min$ at $1,000 \times \mathrm{g}$. After each wash, carefully pipette off and discard exactly $1 \mathrm{ml}$ of supernatant in order to maintain the original bead volume. It is critical to use more beads than needed in order to compensate for pipetting errors and to ensure that the same volume is added to all tubes.

26- Mix chromatin samples with $40 \mu$ lof beads for at least $1 \mathrm{~h}$ with gentle shaking.

27- Pellet and discard the beads (plus non-specifically bead-bound chromatin) and combine the three supernatants (the so-called pre-cleared chromatin) into a Falcon tube.

28- Split the sample into tubes containing 5-10 $\mu \mathrm{g}$ of DNA each. Save 2-4 $\mu$ g as an INPUT control. Always use the same amount of chromatin in each independent experiment. For the INPUT, follow all the incubations without adding any reagent until step 31 .

29- Incubate overnight with $2 \mu$ l of undiluted antibodies or non-immune serum and then with $40 \mu \mathrm{l}$ of new beads for at least $1 \mathrm{~h}$ with gentle shaking.

30 - Pellet the beads and wash for $10 \mathrm{~min}$ sequentially with $1 \mathrm{ml}$ of:

- Low salt buffer

- High salt buffer

- LiCl wash buffer

- TE (two washes)

(see below for detailed buffer compositions)

After the final wash, remove TE thoroughly.

\section{Elution}

31 - Add $250 \mu \mathrm{l}$ of freshly prepared elution buffer to dissociate the bead-bound complexes. Add the elution buffer to the INPUT tube. 
32- Vortex briefly and incubate for $15 \mathrm{~min}$ at $65^{\circ} \mathrm{C}$ with gentle shaking.

33- Pellet the beads, carefully transfer the supernatant to a fresh tube and repeat the elution of the beads. Combine the two eluates. At this step, the samples can be stored at $-20^{\circ} \mathrm{C}$

\section{Crosslinking reversal}

34- Add $20 \mu \mathrm{l}$ of $5 \mathrm{M} \mathrm{NaCl}$ to the eluate and incubate for $6 \mathrm{hr}$ at $65^{\circ} \mathrm{C}$ to reverse the crosslinking. To prevent evaporation, completely submerge the samples in a water bath or use mineral oil if a dry block is used.

35- Add $10 \mu \mathrm{l}$ of $0.5 \mathrm{M}$ EDTA, $20 \mu \mathrm{l}$ of $1 \mathrm{M}$ Tris- $\mathrm{HCl}$ $\mathrm{pH} 6.8$ and $1.5 \mu \mathrm{l}$ of $14 \mathrm{mg} / \mathrm{ml}$ proteinase $\mathrm{K}$ to the eluate and incubate for $1 \mathrm{~h}$ at $45^{\circ} \mathrm{C}$.

\section{DNA recovery}

36- Extract DNA with equal volume of phenol/chloroform/isoamyl alcohol. Centrifuge $5 \mathrm{~min}$ at $5,000 \mathrm{~g}$ to separate the phases (commercial DNA clean-up columns may alternatively be used).

37- Add 0.1 volume of $3 \mathrm{M}$ sodium acetate $\mathrm{pH} 5.3$ to the aqueous phase and precipitate with 0.7 volumes of isopropanol in the presence of tRNA $(1 \mu \mathrm{g} / \mathrm{ml}$ final concentration). Centrifuge $20 \mathrm{~min}$ at $18,000 \mathrm{~g}$.

38- Wash pellet with $300 \mathrm{ul}$ of $70 \%$ ethanol. Centrifuge $5 \mathrm{~min}$ at $12,000 \mathrm{~g}$. Air dry. Resuspend the DNA pellet in $50 \mu \mathrm{l}$ of Tris- $\mathrm{HCl} \mathrm{pH} 8$ or TE supplemented with $10 \mu \mathrm{g} / \mathrm{ml}$ RNase A.

39- DNA is now ready for analysis by PCR.

\section{Key steps}

\section{Crosslinking and its reversal}

As Das et al. [10] highlighted, these steps are crucial. Tissue was vacuum infiltrated with different formaldehyde concentrations until it appeared translucent as air from mesophyll cells was replaced with the aqueous solution. The efficiency of crosslinking was evaluated by phenol extraction, taking advantage of the fact that only non-crosslinked DNA can be recovered in the aqueous phase. The optimal formaldehyde concentration to achieve efficient and reversible crosslinking turned out to be $1 \%$ (Figure 1). Too much formaldehyde was ineffective, probably because of poor crosslinking reversal

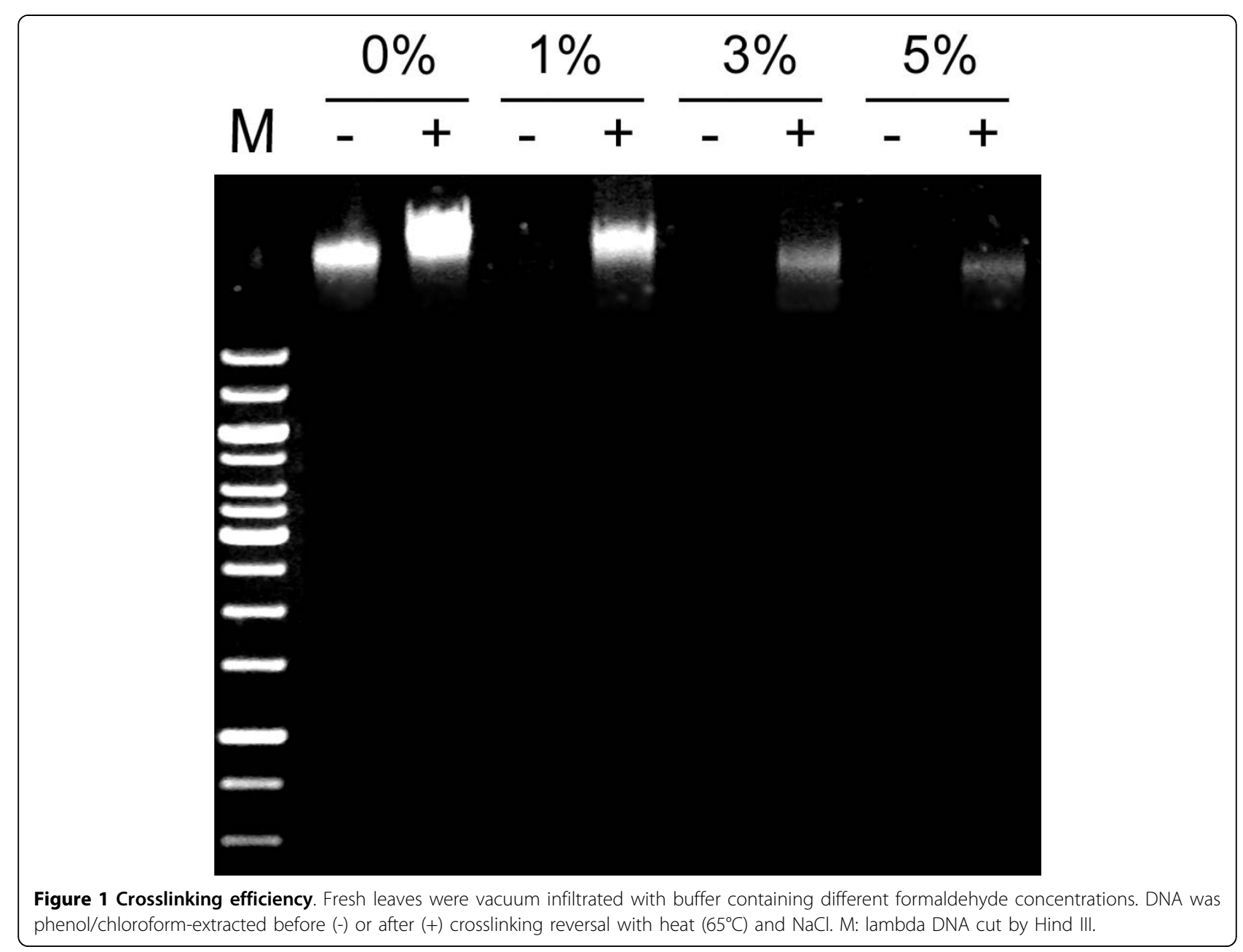


and/or inhibition of chloroplast lysis as observed during the next step (see below), resulting in co-purification of nuclei along with chloroplasts and, thus, less pure chromatin (data not shown).

\section{Chromatin extraction}

We combined the ChIP protocol for Arabidopsis [11] with previously described tomato nuclei isolation protocols [12,13]. The conditions involved filtration steps through nylon mesh, centrifugation in buffers of different density and incubation with the detergent Triton X100 in order to lyse chloroplasts. Recovered intact nuclei were stained with SYBR Green and observed using a confocal microscope as 5-10 $\mu \mathrm{m}$ fluorescent particles (Figure 2).

Once the integrity of the nuclei was confirmed, they were lysed in nuclei lysis buffer (see Methods for details) for subsequent chromatin isolation and shearing by sonication. Prior to the next step (shearing), chromatin quality was checked by micrococcal nuclease digestion. With this enzymatic treatment, non-crosslinked chromatin exhibited typical nucleosome ladders (Figure 3), demonstrating the quality of the samples. This offers the possibility of developing a protocol to perform native ChIP (NChIP). The pros and cons of NChIP vs. regular ChIP with crosslinking (XChIP) are discussed elsewhere [14].

\section{DNA physical shearing}

After testing various sonication conditions, we used 5 rounds of 10 seconds each at 15\% amplitude, which was sufficient to obtain 200- to 1000-bp DNA fragments (Figure 4). Depending on the particular intended use of the ChIP technique, the average fragment size can be altered. For example, whereas larger fragments (1-2 kb) are recommended for cloning purposes, smaller

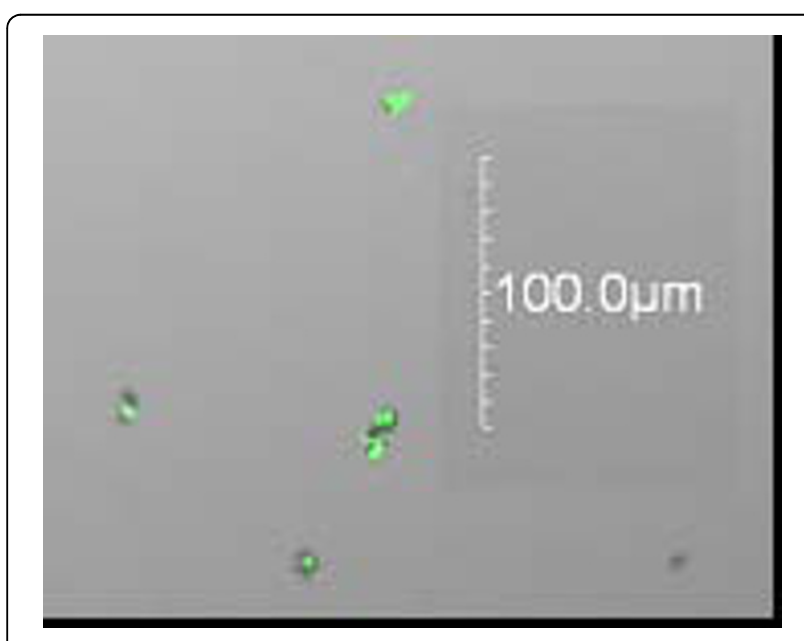

Figure $\mathbf{2}$ Visualisation of nuclei. Nuclei were stained with SYBR Green and observed using a confocal microscope (see Methods) at $60 \times$ through an oil immersion lens. fragments are suggested for high-resolution histone modification maps [15].

\section{Immunoprecipitation}

We used conditions essentially as previously reported [11]. We performed overnight incubation trials with ChIP-grade antibodies raised against Histone H3 (H3) or di-methyl-lysine 9 Histone H3 (H3K9 me2), an ubiquitous epigenetic mark in plants [16] and with nonimmune serum as positive and negative controls, respectively.

\section{Analysis of immunoprecipitated DNA}

After crosslinking reversal and DNA extraction, we performed real-time (quantitative) PCR [17] to evaluate the amount of recovered DNA corresponding to the constitutively active genes ubiquitin (UBI) (GenBank: X58253) and Elongation Factor 1 (EF-1) (GenBank: X14449) [18] as well as the LTR-retrotransposons T135 (GenBank: AY746975) and ToRTL1 (GenBank: U68072), subregions To1 and To3 [19] (Table 1).

All precipitated specific DNA regions showed statistically higher recovery than the non-immune control $(\mathrm{P}=$ 0.0043 for total H3; $\mathrm{P}=0.0025$ for $\mathrm{H} 3 \mathrm{~K} 9$ me2), reaching values of up to $0.2-1 \%$ of the input sample (Figure $5 \mathrm{~A}$ ).

We also show the same results as the "relative enrichment", which is the enrichment relative to non-immune serum (Figure 5B). Although this data presentation format gives rise to high standard deviations, we were able to consistently observe more than 40 -fold enrichment for the five loci precipitated with anti-total $\mathrm{H} 3$ and antiH3K9 me2 antibodies. H3K9 me2/H3 coefficients did not differ significantly between the chosen loci $(\mathrm{P}<$ 0.05), strongly suggesting that the H3K9 methylation status of the LTR-retrotransposons, as well as UBI and EF-1, is similar.

As the finding of H3K9 Me2 in UBI and EF-1 housekeeping genes was unexpected (strictly based on Arabidopsis data [16]), further research on other genes will be needed to establish whether there are fundamental differences between Arabidopsis and tomato histone methylation patterns.

\section{Comments}

Here we provide an optimised ChIP protocol for tomato samples to achieve unambiguous data interpretation. Results obtained with two different antibodies, five control loci and two normalisation criteria are shown. We believe that this procedure will allow both the identification of transcription factors targeting novel genes (given the availability of high-quality antibodies) and histone epigenetic analysis for genes of interest. Some modifications could clearly be introduced into this protocol in order to eventually carry out native ChIP in tomato or conventional ChiP in plants other than tomato. Since a reference tomato genome draft sequence is already 


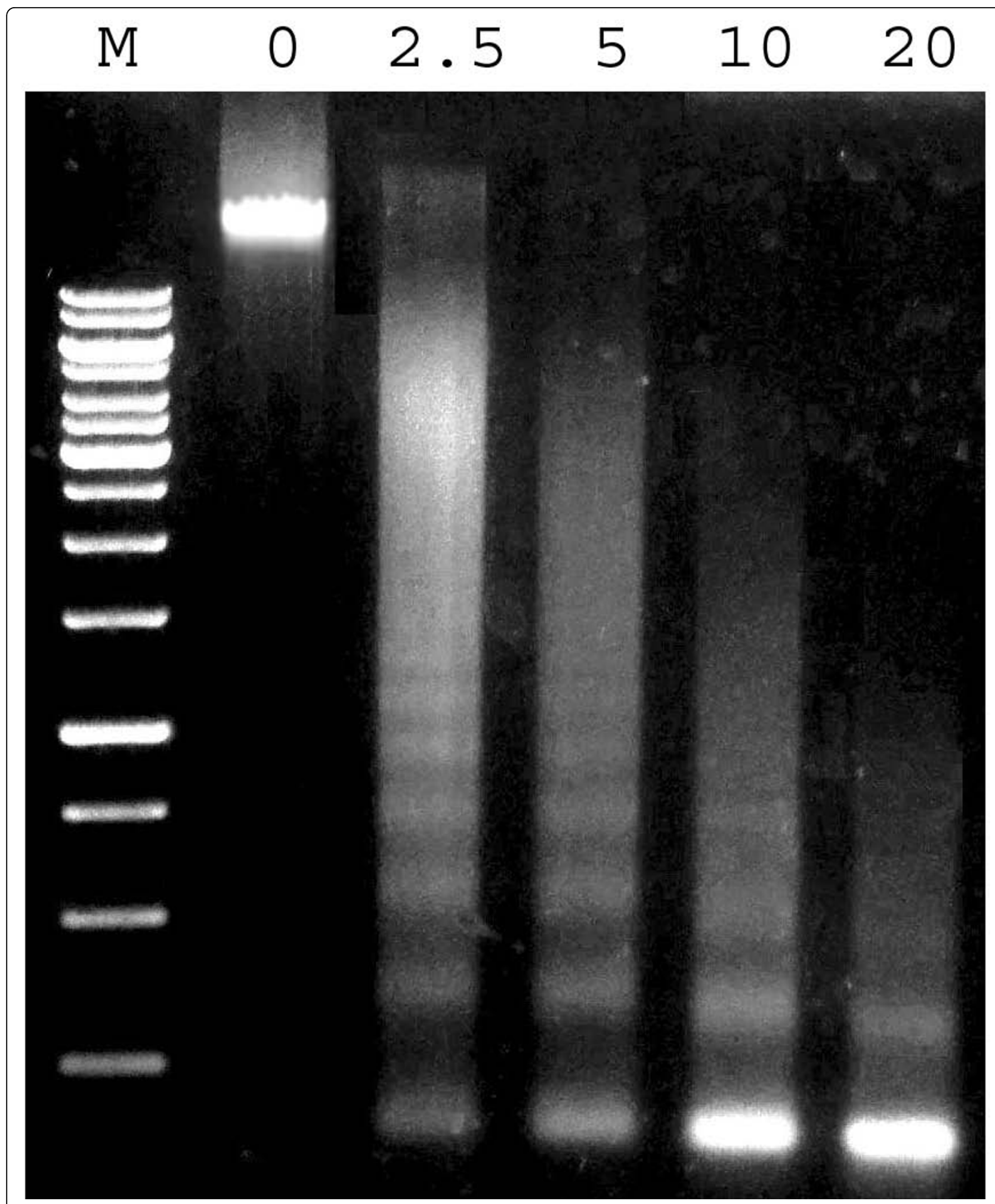

Figure 3 Assessment of chromatin quality. Non-crosslinked chromatin samples were digested for 20 min with 0, 2.5, 5, 10 and 20 units of micrococcal nuclease. M: 1-kb DNA ladder (MBI Fermentas, Inc.). 


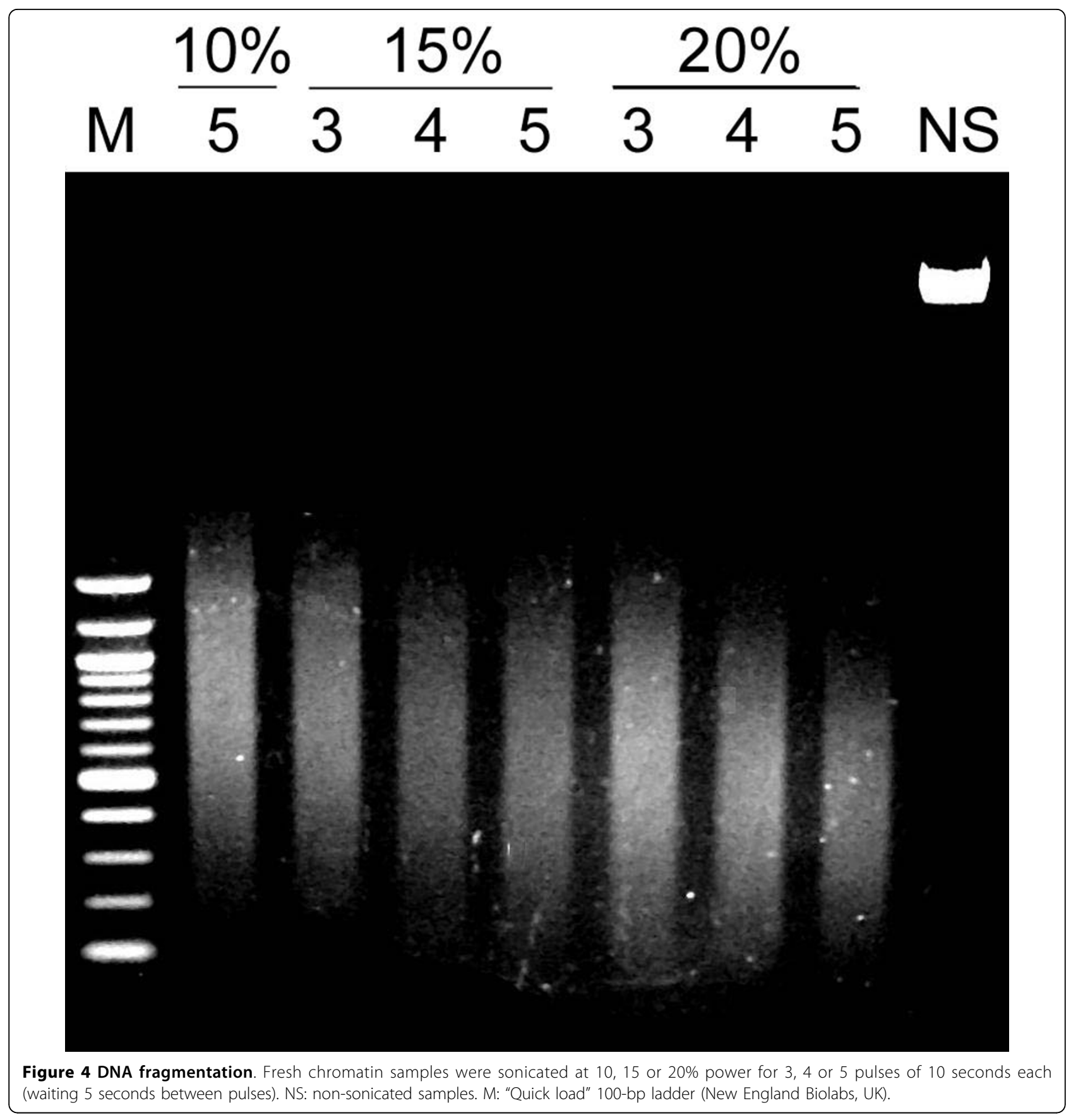

Table 1 DNA quantification by real-time PCR.

\begin{tabular}{lllc}
\hline locus & \multicolumn{1}{c}{ forward primer } & \multicolumn{1}{c}{ reverse primer } & exponential slope \\
\hline T135 & CCAGCCATAACAACCAACTTC & GCAGACCACCAAATCCAACTC & 1.93 \\
To1 & CCATCCTTACTTCCATCATTG & ATCACATAGACCTCCTCGTTC & 1.99 \\
To3 & ATGAAGAGGAAGAAGATACCG & TGGCAATGATGAGTGAAGAG & 1.94 \\
EF-1 & GATTGGTGGATTGGAACTGTC & AGCTTCGTGGGCATCTC & 1.93 \\
UBI3 & GCCGACTACAACATCCAGAAGG & TGCAACACAGCGAGCTTAACC & 1.94 \\
\hline
\end{tabular}

The locus-specific primers used and slope values resulting from standard curves using serial dilutions of INPUT samples [17] are indicated. 

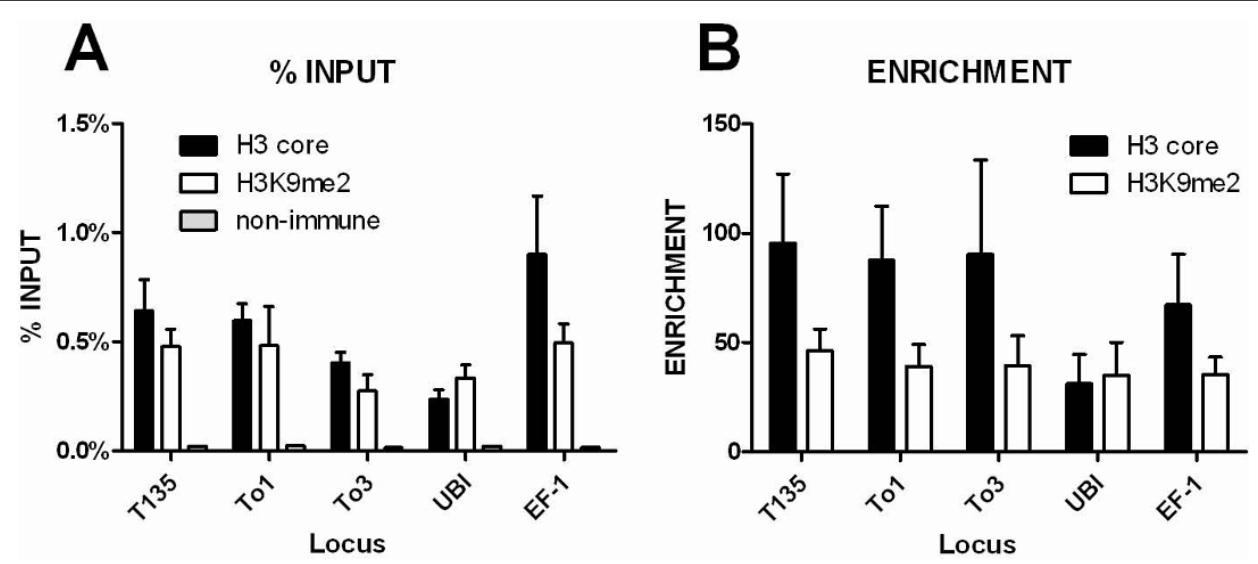

Figure 5 Immunoprecipitated DNA analysis by real-time PCR. Mean recovery values and standard errors of at least five replicates derived from three different chromatin isolation experiments. The indicated results were obtained from samples precipitated with anti-H3 (black closed bars), anti-H3K9 me2 (open bars) or non-immune serum (gray close bars, if noticeable). A: Results normalised relative to INPUT. B: Same results presented as enrichment relative to non-immune serum.

available http://solgenomics.net/about/tomato_sequencing.pl, ChIP could be combined with high-throughput sequencing to generate a detailed map of epigenetic modifications or genome-wide nucleosome positioning data [20].

\section{Acknowledgements}

This work was supported by grants from Universidad de Buenos Aires (UBA), Agencia Nacional de Promoción Científica y Tecnológica (ANPCyT) and Consejo Nacional de Investigaciones Científicas y Tecnológicas (CONICET), Argentina.

\section{Authors' contributions}

MMR did the major experimental work. RMG contributed to the epigenetic context of the paper. NDI coordinated the project and drafted the manuscript. All authors read and approved the final manuscript.

\section{Authors' information}

MMR and RMG hold doctorate fellowships from Consejo Nacional de Investigaciones Científicas y Técnicas (CONICET), Argentina. NDI is a member of the Carrera del Investigador Científico, CONICET, Argentina.

\section{Competing interests}

The authors declare that they have no competing interests.

Received: 21 December 2009 Accepted: 9 April 2010 Published: 9 April 2010

\section{References}

1. Priest HD, Filichkin SA, Mockler TC: Cis-regulatory elements in plant cell signaling. Curr Opin Plant Biol 2009, 12:643-649.

2. Takeda S, Paszkowski J: DNA methylation and epigenetic inheritance during plant gametogenesis. Chromosoma 2006, 115:27-35.

3. Turck F, Roudier F, Farrona S, Martin-Magniette ML, Guillaume E, Buisine N, Gagnot S, Martienssen RA, Coupland G, Colot V: Arabidopsis TFL2/LHP1 specifically associates with genes marked by trimethylation of histone H3 lysine 27. PLoS Genet 2007, 3:e86.

4. Barone A, Di Matteo A, Carputo D, Frusciante L: High-throughput genomics enhances tomato breeding efficiency. Curr Genomics 2009, 10:1-9.

5. Hoeven Van der R, Ronning C, Giovannoni J, Martin G, Tanksley S: Deductions about the number, organization, and evolution of genes in the tomato genome based on analysis of a large expressed sequence tag collection and selective genomic sequencing. Plant Cell 2002, 14:1441-1456.

6. Fridman E, Zamir D: Functional divergence of a syntenic invertase gene family in tomato, potato, and Arabidopsis. Plant Physiol 2003, 131:603-609.

7. Leseberg $\mathrm{CH}$, Eissler $\mathrm{CL}$, Wang $\mathrm{X}$, Johns MA, Duvall MR, Mao L: Interaction study of MADS-domain proteins in tomato. J Exp Bot 2008, 59:2253-2265.

8. Caramelo JJ, lusem ND: When cells lose water: Lessons from biophysics and molecular biology. Prog Biophys Mol Biol 2009, 99:1-6.

9. Haring M, Offermann S, Danker T, Horst I, Peterhansel C, Stam M: Chromatin immunoprecipitation: optimization, quantitative analysis and data normalization. Plant Methods 2007, 3:11.

10. Das PM, Ramachandran K, vanWert J, Singal R: Chromatin immunoprecipitation assay. Biotechniques 2004, 37:961-969.

11. Bowler C, Benvenuto G, Laflamme P, Molino D, Probst AV, Tariq M, Paszkowski J: Chromatin techniques for plant cells. Plant J 2004, 39:776-789.

12. Conconi A, Ryan CA: DNase I and micrococcal nuclease analysis of the tomato proteinase inhibitor I gene in chromatin. J Biol Chem 1993, 268:430-435.

13. Schumacher J, Sanger HL, Riesner D: Subcellular localization of viroids in highly purified nuclei from tomato leaf tissue. EMBO J 1983, 2:1549-1555.

14. O'Neill LP, Turner BM: Immunoprecipitation of native chromatin: NChIP. Methods 2003, 31:76-82.

15. Barski A, Cuddapah S, Cui K, Roh TY, Schones DE, Wang Z, Wei G, Chepelev I, Zhao K: High-resolution profiling of histone methylations in the human genome. Cell 2007, 129:823-837.

16. Mathieu O, Probst AV, Paszkowski J: Distinct regulation of histone H3 methylation at lysines 27 and 9 by CpG methylation in Arabidopsis. EMBO J 2005, 24:2783-2791.

17. Larionov A, Krause A, Miller W: A standard curve based method for relative real time PCR data processing. BMC Bioinformatics 2005, 6:62.

18. Pokalsky AR, Hiatt WR, Ridge N, Rasmussen R, Houck CM, Shewmaker CK: Structure and expression of elongation factor 1 alpha in tomato. Nucleic Acids Res 1989, 17:4661-4673.

19. Tam SM, Causse M, Garchery C, Burck H, Mhiri C, Grandbastien MA: The distribution of copia-type retrotransposons and the evolutionary history of tomato and related wild species. J Evol Biol 2007, 20:1056-1072.

20. Schones DE, Cui K, Cuddapah S, Roh TY, Barski A, Wang Z, Wei G, Zhao K: Dynamic regulation of nucleosome positioning in the human genome. Cell 2008, 132:887-898.

doi:10.1186/1746-4811-6-11

Cite this article as: Ricardi et al:: Protocol: fine-tuning of a Chromatin Immunoprecipitation (ChIP) protocol in tomato. Plant Methods 2010 6:11. 